\title{
Wnt5a promotes Frizzled-4 signalosome assembly by stabilizing cysteine-rich domain dimerization
}

\author{
Zachary J. DeBruine, ${ }^{1,7}$ Jiyuan Ke, ${ }^{2,7}$ Kaleeckal G. Harikumar, ${ }^{3,7}$ Xin Gu, ${ }^{1}$ Peter Borowsky, ${ }^{1}$ \\ Bart O. Williams, ${ }^{4}$ Wenqing $\mathrm{Xu},{ }^{5}$ Laurence J. Miller, ${ }^{3} \mathrm{H}$. Eric $\mathrm{Xu}^{2,6}$ and Karsten Melcher ${ }^{1}$ \\ ${ }^{1}$ Center for Cancer and Cell Biology, Laboratory for Structural Biology and Biochemistry, Van Andel Research Institute, Grand \\ Rapids, Michigan 49503, USA; ${ }^{2}$ Center for Cancer and Cell Biology, Laboratory of Structural Sciences, Van Andel Research \\ Institute, Grand Rapids, Michigan 49503, USA ${ }^{3}$ Department of Molecular Pharmacology and Experimental Therapeutics, Mayo \\ Clinic, Scottsdale, Arizona 85259, USA; ${ }^{4}$ Center for Skeletal Disease Research, Laboratory of Cell Signaling and Carcinogenesis, \\ Van Andel Research Institute, Grand Rapids, Michigan 49503, USA; ${ }^{5}$ Department of Biological Structure, University of \\ Washington, Seattle, Washington 98195, USA; ${ }^{6}$ Van Andel Research Institute/Shanghai Institute of Materia Medica Center, Key \\ Laboratory of Receptor Research, Shanghai Institute of Materia Medica, Chinese Academy of Sciences, Shanghai 201203, China
}

Wnt/ $\beta$-catenin signaling is activated when extracellular Wnt ligands bind Frizzled (FZD) receptors at the cell membrane. Wnts bind FZD cysteine-rich domains (CRDs) with high affinity through a palmitoylated N-terminal "thumb" and a disulfide-stabilized C-terminal "index finger," yet how these binding events trigger receptor activation and intracellular signaling remains unclear. Here we report the crystal structure of the Frizzled-4 $\left(\mathbf{F Z D}_{4}\right)$ CRD in complex with palmitoleic acid, which reveals a CRD tetramer consisting of two cross-braced CRD dimers. Each dimer is stabilized by interactions of one hydrophobic palmitoleic acid tail with two CRD palmitoleoyl-binding grooves oriented end to end, suggesting that the Wnt palmitoleoyl group stimulates CRD-CRD interaction. Using bioluminescence resonance energy transfer (BRET) in live cells, we show that WNT5A stimulates dimerization of membrane-anchored $\mathrm{FZD}_{4}$ CRDs and oligomerization of full-length $\mathrm{FZD}_{4}$, which requires the integrity of CRD palmitoleoyl-binding residues. These results suggest that FZD receptors may form signalosomes in response to Wnt binding through the CRDs and that the Wnt palmitoleoyl group is important in promoting these interactions. These results complement our understanding of lipoprotein receptor-related proteins 5 and 6 (LRP5/6), Dishevelled, and Axin signalosome assembly and provide a more complete model for Wnt signalosome assembly both intracellularly and at the membrane.

[Keywords: Wnt; Frizzled; signalosome; cysteine-rich domain; WNT5A; Frizzled-4]

Supplemental material is available for this article.

Received March 3, 2017; revised version accepted May 3, 2017.

Wnt signaling regulates many developmental, cellular, and pathogenic processes, including embryogenesis (Clevers 2006), stem cell maintenance (Willert et al. 2003), and oncogenesis (Vermeulen et al. 2010). Consequently, targeting the Wnt pathway is of great therapeutic interest, and many promising approaches have emerged recently (Anastas and Moon 2013). However, the structural basis of Wnt signal activation and the corresponding targetable mechanism remain poorly understood. Wnt signal activation begins at the membrane when a Wnt ligand engages a Frizzled (FZD) receptor (class FZD G-protein-coupled receptor [GPCR]) (He et al. 1997; Cong et al. 2004; Janda et al. 2012). FZD then undergoes conformational changes, which are largely unknown, to trigger intracellular Wnt

\footnotetext{
${ }^{7}$ These authors contributed equally to this work.

Corresponding authors: karsten.melcher@vai.org, eric.xu@vai.org Article published online ahead of print. Article and publication date are online at http://www.genesdev.org/cgi/doi/10.1101/gad.298331.117.
}

signalosome assembly (Gammons et al. 2016a). Dishevelled is a three-domain protein that binds FZD through its PDZ and DEP domains (Gammons et al. 2016b) and polymerizes through its DIX domain in response to FZD activation (Schwarz-Romond et al. 2007). Axin also contains a DIX domain that can copolymerize with Dishevelled DIX domains (Fiedler et al. 2011) and, in the case of Wnt $/ \beta$-catenin signaling, functions to sequester the $\beta$ catenin destruction complex to permit $\beta$-catenin stabilization, nuclear translocation, and transcriptional regulation (Feng and Gao 2015).

(C) 2017 DeBruine et al. This article is distributed exclusively by Cold Spring Harbor Laboratory Press for the first six months after the full-issue publication date (see http://genesdev.cshlp.org/site/misc/terms.xhtml). After six months, it is available under a Creative Commons License (Attribution-NonCommercial 4.0 International), as described at http://creativecommons.org/licenses/by-nc/4.0/. 
A major gap in knowledge is the mechanism of FZD activation. Several structural snapshots inform our understanding, such as the structure of Xenopus Wnt8 (XWnt8) bound to the Frizzled- $8\left(\mathrm{FZD}_{8}\right)$ cysteine-rich domain (CRD) (Janda et al. 2012), the structure of Smoothened extracellular and transmembrane domains (TMDs) (Byrne et al. 2016), the structure of dimeric Norrin and its complex with the Frizzled-4 (FZD 4 ) CRD (Ke et al. 2013; Chang et al. 2015; Shen et al. 2015), and the structures of the Dishevelled DEP (Gammons et al. 2016a), DIX (Madrzak et al. 2015), and PDZ (Zhang et al. 2009) domains. However, it is unclear how extracellular Wnt binding activates FZD to initiate transmembrane Wnt signalosome assembly. The structure of XWnt8 in complex with the $\mathrm{FZD}_{8}$ CRD reveals two sites of Wnt-FZD engagement: one site in which an extended disulfide-stabilized loop from the $\mathrm{C}$ terminus of XWnt 8 binds three $\mathrm{FZD}_{8}$ CRD surface loops and a second site that features a lipid-binding groove on the FZD 8 CRD that fits a palmitoleic acid covalently attached to the Wnt. This palmitoleoyl-binding groove appears to be functionally conserved across all FZD CRDs (Bazan et al. 2012), which underscores the biological significance of Wnt palmitoleoylation (Hannoush and Arenas-Ramirez 2009; Gao and Hannoush 2014). However, the XWnt8/FZD 8 CRD crystal structure was solved from a 1:1 monomeric complex, although previous reports have suggested that Wnt can bind to FZD CRDs in a 2:1 stoichiometry (Uren et al. 2000); thus, it remains unclear how Wnt binding to FZD induces receptor oligomerization and subsequent signal activation.

Norrin is a growth factor unrelated to WNT that also binds the $\mathrm{FZD}_{4} \mathrm{CRD}$ and low-density lipoprotein receptor-related proteins 5 and 6 (LRP5/6) and stimulates the $\mathrm{WNT} / \beta$-catenin pathway (Xu et al. 2004). Norrin forms constitutive dimers that bring two CRDs into relatively close proximity (30 ̊) without direct CRD-CRD contact, suggesting that it induces CRD proximity and possibly FZD clustering (Ke et al. 2013; Shen et al. 2015). Additional structural insight into FZD regulation comes from Smoothened, the ancestral class F GPCR and the only member of the family not to participate in Wnt signaling. Smoothened possesses the shortest CRD-to-transmembrane linker and the longest extracellular loop 3 (ECL3) of any FZD and depends on ECL3-CRD contacts for activation (Byrne et al. 2016). The role of the CRD in regulating the FZD TMD as well as the relevance of the Smoothened mechanism of regulation to classical FZDs remain unclear. The structures of Dishevelled domains provide insights into intracellular FZD regulation. Dishevelled is the intracellular hub of Wnt signalosome assembly: Its PDZ domains anchor to FZD (Zhang et al. 2009), its DEP domains dimerize at the FZD intracellular cores when Wnt binds FZD (Gammons et al. 2016a), and its DIX domains respond to DEP dimerization by copolymerizing with Axin (Gammons et al. 2016b). These globular domains are separated by highly flexible linkers, resembling "balls on a string." Dishevelled seems to require extensive coordination with high local concentrations of FZD in order to generate large signalosomes, dependent in part on sufficient binding surfaces for DEP dimerization and PDZ anchoring to enable DIX polymerization (Simons et al. 2009). This would also suggest that FZDs respond to Wnt-binding events by oligomerizing to provide Dishevelled and Axin with a scaffold to stabilize and facilitate copolymerization (Bilic et al. 2007; Yang et al. 2016).

Many Wnt signaling pathways also require a coreceptor that contains a C-terminal tail with post-translational modifications, functional domains, or protein-interacting motifs, which dictate pathway specificity and activity. LRP5 and LRP6 are coreceptors specifically for the Wnt/ $\beta$-catenin pathway and Wnt/STOP signaling (Huang et al. 2015) and form signalosomes at the membrane when active (Bilic et al. 2007). These coreceptors are thus recruited to FZD by Wnts, and their C-terminal tail functions intracellularly in tandem with FZDs to initiate signaling/Cong et al. 2004; He et al. 2004). LRP5/6 bind Wnts at interfaces within four $\beta$-propeller $(\beta \mathrm{P})$ domains, consisting of two rigid pairs ( $\beta \mathrm{P} 1 / 2$ and $\beta \mathrm{P} 3 / 4)$ linked by a flexible hinge (Chen et al. 2011; Cheng et al. 2011 Matoba et al. 2017). The flexibility of this hinge depends in part on protein binding but also on post-translational modifications near the hinge as well as dimerization status (Matoba et al. 2017). LRP5/6 form both inactive and active dimers with different $\beta \mathrm{P}$ conformations, and these conformations may be regulated by FZDs and Wnts (Matoba et al. 2017).

FZD CRDs are structurally rigid and connected by a long flexible linker to the TMDs (Byrne et al. 2016). This suggests that the CRD may function independently of the TMD, and thus it is not immediately obvious how Wnts activate FZDs through interacting with the CRD. It is also not clear how the CRD could transmit a signal to the TMD to drive intracellular Dishevelled signaling. Here we present data that suggest that the CRD functions to drive FZD oligomerization in response to Wnt binding. We discuss how this model is consistent with current understanding of intracellular signalosome assembly and discuss the implications for therapeutic development and further structural studies.

\section{Results}

$\mathrm{FZD}_{4} \mathrm{CRD}$ s crystallize with palmitoleic acid as a dimer of dimers

As noted by Janda et al. (2012), the binary structure of XWnt8 in complex with the FZD 8 CRD (Protein Data Bank [PDB] 4F0A) leaves the hydrophobic end of the palmitoleic acid extending solvent-exposed beyond the CRD palmitoleoyl-binding groove, which would be energetically highly unfavorable in an aqueous environment. In the crystal lattice, the lipid tail is completely buried by interaction with nonconserved residues of an adjacent XWnt8, but the physiological relevance of this interaction is unclear (Janda et al. 2012). To investigate whether Wnts might mediate CRD dimerization through the palmitoleoyl modification, we crystallized the $\mathrm{FZD}_{4} \mathrm{CRD}$ with palmitoleic acid. We obtained a crystal structure at $2.56 \AA$ resolution showing that one palmitoleic acid coordinates with two $\mathrm{FZD}_{4}$ CRDs through several conserved 
residues in the lipid-binding groove (Fig. 1A,B). The FZD 4 CRD lipid-binding grooves are oriented end to end, with $\sim 10$ residues of each CRD forming a surface at the interaction interface. We were able to clearly resolve the densities of the palmitoleic acid situated in the lipid-binding groove and the neighboring side-chains (Fig. 1C). A network of hydrophobic residues within the lipid-binding grooves of both CRDs coordinates with the palmitoleic acid at similar distances (Fig. 1D). Strikingly, these residues are shared by both CRDs (T81, F82, L85, L132, F135, and F137) and appear to have specificity for the linear, saturated hydrocarbon chains on either end of the
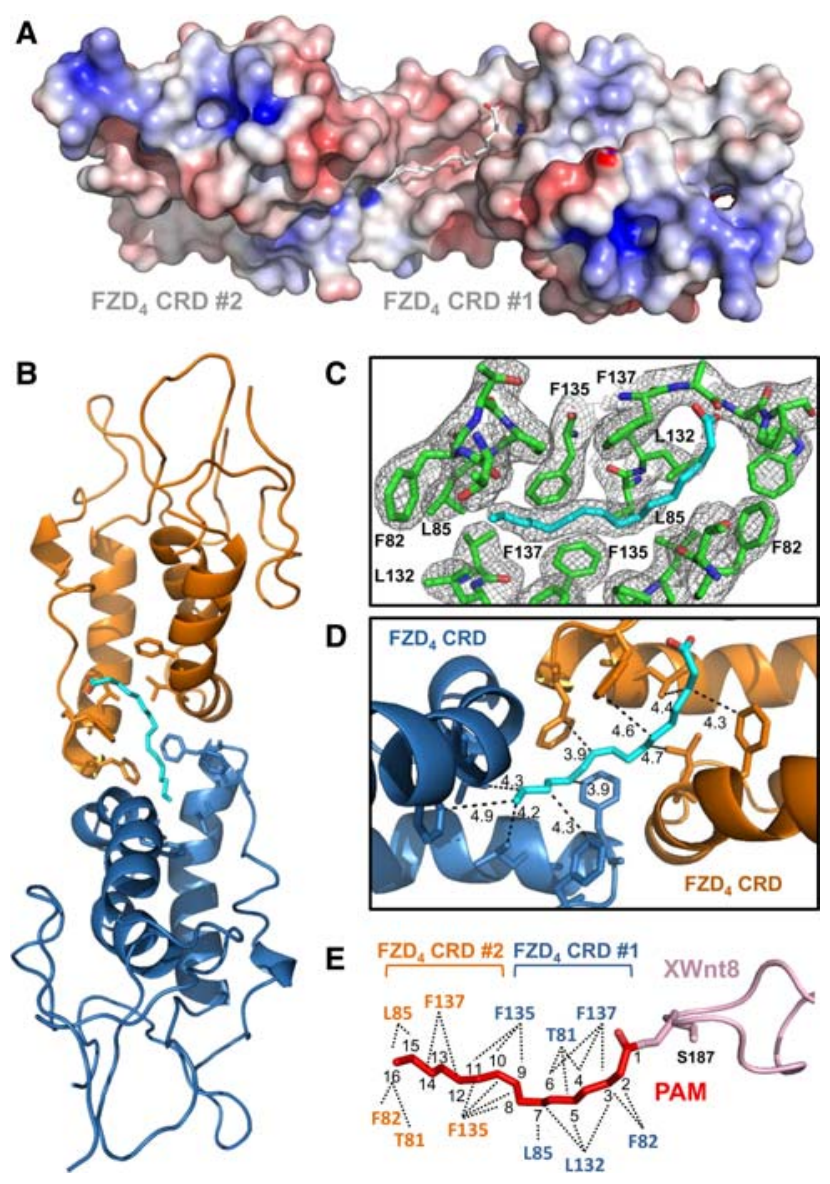

Figure 1. Crystal structure of the $\mathrm{FZD}_{4} \mathrm{CRD}$ dimer with palmitoleic acid. $(A)$ Electrostatic surface rendering of $\mathrm{FZD}_{4}$ dimers showing end-to-end orientation of palmitoleoyl-binding grooves and chemical complementarity with palmitoleic acid (white stick model). Based on the palmitoleic acid orientation, Wnts would make residue-residue contact with only $\mathrm{FZD}_{4}$ CRD \#1, while $\mathrm{FZD}_{4} \mathrm{CRD} \# 2$ contacts only palmitoleic acid. $(B)$ Cartoon of $\mathrm{FZD}_{4} \mathrm{CRD}$ dimers (orange and blue), with hydrophobic residues in the palmitoleoyl-binding groove shown as sticks. $(C)$ Electron density map showing hydrophobic residues in palmitoleoylbinding grooves of both CRDs that coordinate with palmitoleic acid. (D) Distances (in angstroms) between hydrophobic residues in the palmitoleoyl-binding grooves of $\mathrm{FZD}_{4} \mathrm{CRD}$ dimers. $(E)$ Schematic of shared hydrophobic coordination networks in both $\mathrm{FZD}_{4}$ CRDs, which facilitate bimolecular palmitoleic acid docking (here modeled onto Xenopus Wnt8; PDB 4F0A).
C9-C10 unsaturated bond in palmitoleic acid (Fig. 1E). The unsaturated kink in palmitoleic acid is situated across the CRD-CRD interaction surface, and the angle of this kink appears to be crucial for stabilizing the CRD-CRD interaction.

We compared the mode of palmitoleic acid binding in our $\mathrm{FZD}_{4}$ dimer and the previously described mode of acylated XWnt8 binding to a single $\mathrm{mFZD}_{8} \mathrm{CRD}$ (Janda et al. 2012). Upon alignment of the palmitoleic acid in our structure and the acyl moiety in the Janda et al. (2012) structure, we were surprised to discover that XWnt8 seems to be acylated with saturated palmitic acid (Supplemental Fig. S3C) even though Wnt proteins are preferentially acylated with cis-unsaturated fatty acids, especially palmitoleic acid (Takada et al. 2006; Rios-Esteves and Resh 2013; Kakugawa et al. 2015). $\mathrm{FZD}_{4}$ and $\mathrm{mFZD}_{8}$ are very similar structurally, and the hydrophobic residues in $\mathrm{FZD}_{4}$ that coordinate with palmitoleic acid are positioned very similarly in $\mathrm{mFZD}_{8}$, with the exception of $\mathrm{L} 132$ and

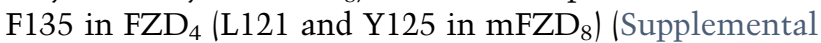
Fig. S3A). The almost $180^{\circ}$ rotation of the L121 side-chain as well as the $90^{\circ}$ planar rotation of $\mathrm{F} 135$ in $\mathrm{FZD}_{4}$ move these residues closer to the shifted position of palmitoleic acid relative to palmitic acid (Supplemental Fig. S3A,B). With the exception of the lack of a kink, the saturated palmitic acid in complex with $\mathrm{FZD}_{8}$ is positioned very similarly to the monounsaturated palmitoleic acid in $\mathrm{FZD}_{4}$, although the carboxyl group appears shifted by approximately three carbons. The significance of the altered positioning of the lipid in these two structures is unclear, but we noticed that XWnt8 is still able to bind $\mathrm{FZD}_{4}$ when the lipid is in this position (see Supplemental Figs. S2, S4).

It is clear, however, that unsaturated Wnt acylation will have very different functional outcomes from saturated acylation. Specifically, we predict that saturated acyl moieties cannot mediate CRD dimerization and may be protected by non-CRD FZD domains, much like cholesterol in Smoothened (Byrne et al. 2016). Conversely, unsaturated acylation would permit dimerization through its bent conformation, which can fit two FZD CRD lipid-binding grooves aligned end to end.

\section{Whts may bind tetrameric assemblies of FZD CRDs}

When bound to only a single $\mathrm{FZD}_{4} \mathrm{CRD}$ dimer, palmitoleic acid (and the hydrophobic lipid-binding $\mathrm{FZD}_{4}$ residues) remains partially solvent-accessible. However, in our crystal structure, two of these dimers can interlock across one another to form a tetrameric complex in which the palmitoleic acid is entirely encased in a hydrophobic pocket, and the hydrophobic residues are solvent-protected (Fig. 2A). The dimers contact one another at conserved surfaces surrounding the lipid-binding grooves (Fig. 2B), suggesting that these interactions are important. Both palmitoleic acid molecules in the tetramer are oriented with carboxyl heads positioned toward the opening of the pocket (Fig. 2C,D). We refined our structure using either the dimer or the tetramer as the asymmetric unit, but both approaches gave very similar results (Supplemental Fig. S1A). It appears, however, that the tetramer will be 

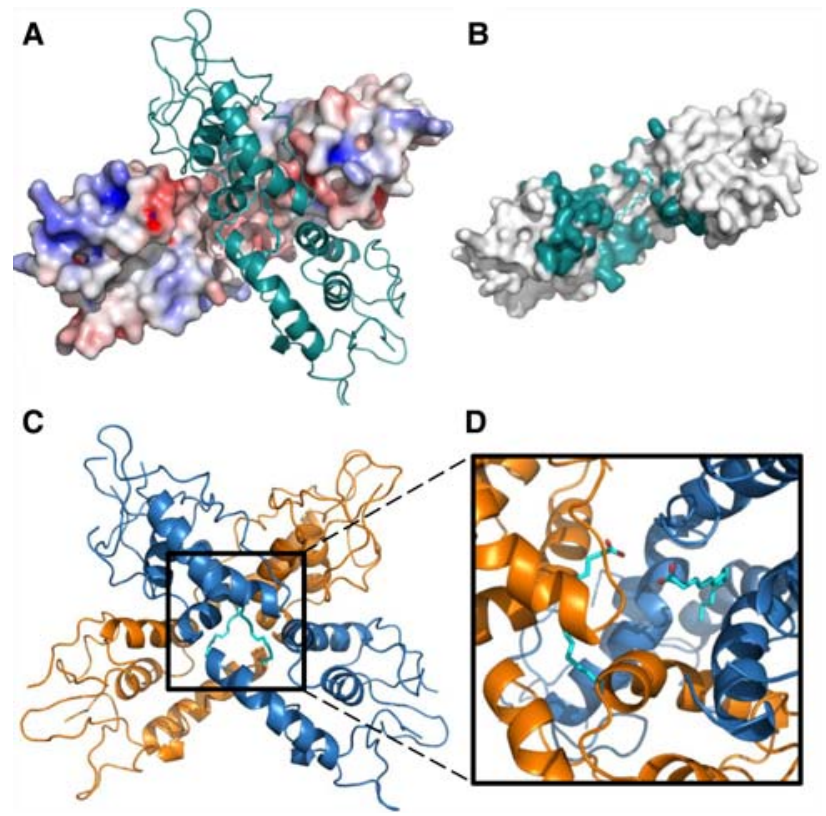

Figure 2. Structure of $\mathrm{FZD}_{4} \mathrm{CRD}$ tetrameric assembly. $(A)$ Tetrameric complex of four $\mathrm{FZD}_{4} \mathrm{CRDs}$, with two palmitoleic acids (sticks; cyan) shown as a dimer of dimers (one dimer is colored with electrostatic surface, and the other dimer is in teal). (B) Surface rendering of residues on one dimer within $5 \AA$ of the other dimer (shown in teal). (C) The tetrameric complex of four $\mathrm{FZD}_{4}$ CRDs (dimers in blue and orange) with two palmitoleic acids (sticks; cyan). (D) Rotated inset from $A$. Palmitoleic acid molecules are oriented within the tetramer with heads facing the opening of the pocket.

more physiologically relevant unless some CRD-independent mechanism exists for protecting CRD hydrophobic residues and palmitoleic acid from solvent. We noticed that our structure of $\mathrm{FZD}_{4} \mathrm{CRD}$ tetramers aligns only roughly to a previously published structure (Supplemental Fig. S1B; Chang et al. 2015), whereas the dimer units in our structure are very similar to those in the Chang et al. (2015) structure (Supplemental Fig. S1C). The difference in tetramer conformation between both structures is due to the "cracking open" of the pocket between dimers at which the palmitoleic acid heads are present.

The biological relevance of this tetrameric assembly is difficult to assess, but we noticed that this structure is consistent with previously published structures and that Wnt can be docked to a single site in the tetramer. This tetramer is asymmetrical about one axis and thus is comprised of four unique monomer-monomer orientations. Two of these orientations have been crystallized previously as dimers in independent crystal forms (Chang et al. 2015; Shen et al. 2015), a third (the palmitoleoyl-bound dimer form) has been crystallized only by Chang et al. (2015) as part of a tetrameric assembly, and the fourth is likely to be unstable by itself and has not been crystallized independently (Supplemental Fig. S2A). To gain insight into whether this tetrameric structure could be biologically relevant, we attempted to dock XWnt8 to a $\mathrm{FZD}_{8}$ CRD tetrameric assembly. This was possible because the CRDs of $\mathrm{FZD}_{4}$ and $\mathrm{FZD}_{8}$ are highly similar and enabled structural alignment (see Supplemental Fig. S3A). We noticed that while the tetramer has two openings to the internal pocket, the asymmetry of the tetramer causes steric clashing at one site but permits docking at the second site with almost no steric clashing (Supplemental Fig. $\mathrm{S} 2 \mathrm{~B})$, indicating that one XWnt8 molecule binding to a tetrameric $\mathrm{FZD}_{4} \mathrm{CRD}$ is sterically compatible. In this binding mode, Wnt directly stabilizes a single dimer interaction, which then supports the assembly of the full tetrameric complex. We also compared this model with the mode of $\mathrm{FZD}_{4}$ CRD binding to Norrin (Supplemental Fig. S4). Norrin is unrelated to classical Wnts in that it homodimerizes and is not palmitoylated. Norrin homodimers engage two independent $\mathrm{FZD}_{4} \mathrm{CRD}$ s in an orientation unlike this tetrameric assembly.

\section{WNT5A and WNT8A mediate FZD 4 CRD-CRD interactions}

To test whether palmitoylated Wnts can promote $\mathrm{FZD}_{4}$ CRD-CRD interactions in the membranes of live cells, we designed a bioluminescence resonance energy transfer (BRET) experiment in which $\mathrm{FZD}_{4}$ CRDs were fused to an unrelated single-pass TMD (CD8) tagged with Renilla luciferase (Rlu) or yellow fluorescent protein (YFP). We further developed a three-hybrid BRET assay using Rlu, YFP $\mathrm{N}$-terminal half $\left(\mathrm{YFP}^{\mathrm{N}}\right)$, and YFP C-terminal half $\left(\mathrm{YFP}^{\mathrm{C}}\right)$ tags. We anticipated that both CRD dimerization and oligomerization events would be captured by the two-hybrid system, while BRET signals in the three-hybrid system require oligomerization and cannot be triggered by dimerization. At the elevated expression levels of the transfected CRD constructs, there is clear evidence for FZD CRDCRD interaction in the absence of Wnt (Fig. 3A). Autodimerization of FZD CRDs has been predicted by other groups (Dann et al. 2001; Chang et al. 2015). Wnts may be able to bind pre-existing FZD CRD dimers, which is structurally plausible (Fig. 3B). We used WNT5A and WNT8A in our experiments, as they both are reported to activate the Wnt/ $\beta$-catenin pathway (He et al. 1997; Mikels and Nusse 2006). We noticed a further increase in CRD-CRD interaction after incubation with WNT5A or WNT8A, indicating that Wnts do indeed stabilize CRDCRD interaction. In contrast, using the three-hybrid BRET approach, we found no clear evidence for oligomerization. However, we note that many GPCRs dimerize or oligomerize through their TMDs (Pfleger and Eidne 2005; Ferre et al. 2009; Ke et al. 2013) and that the potentially weak oligomerization propensities of CRDs may require close proximity brought by FZD TMD dimerization. Thus, we suggest that Wnts can mediate CRD dimerization independently of the FZD TMDs but we cannot exclude higher-order CRD oligomerization.

\section{WNT5A-mediated $\mathrm{FZD}_{4}$ oligomerization requires palmitoleoyl-binding residues}

We next investigated the role of Wnts in mediating fulllength $\mathrm{FZD}_{4}$ oligomerization using a BRET assay in which 


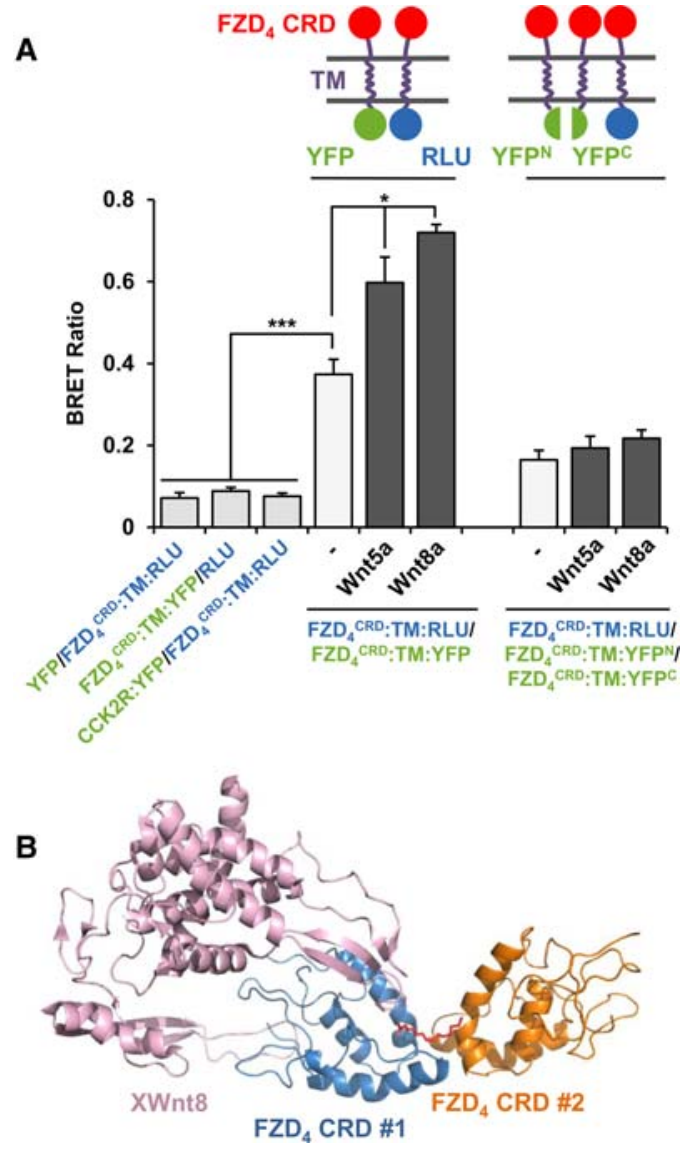

Figure 3. WNT5 A and WNT8A induce $\mathrm{FZD}_{4} \mathrm{CRD}$ interactions. (A) BRET ratios for two-hybrid and three-hybrid experiments in which $\mathrm{FZD}_{4}$ CRDs were fused to a single-transmembrane helix tagged with either Rlu, YFP, or split YFP. Wnts were cotransfected. $\left(^{*}\right) P<0.05$; $\left(^{* * *}\right) P<0.001 . n \geq 6$. Error bars indicate SEM. (B) Structure of XWnt8 (PDB 4F0A) aligned to the $\mathrm{FZD}_{4}$ dimer showing that Wnt can bind this dimer form by contacting a second CRD through the palmitoleoyl modification but without making direct amino acid-amino acid contact.

we cotransfected Rlu- or YFP-tagged $\mathrm{FZD}_{4}$ (Fig. 4A). We used soluble Rlu or YFP as controls in addition to a membrane-bound unrelated YFP-tagged GPCR, cholecystokinin 2 receptor (CCK2R), which we showed previously not to interact with $\mathrm{FZD}_{4}$ (Ke et al. 2013). In the absence of Wnt, we observed $\mathrm{FZD}_{4}-\mathrm{FZD}_{4}$ homodimerization, consistent with our previous results (Ke et al. 2013). Stimulation with active WNT5A protein did not significantly increase $\mathrm{FZD}_{4}$ interactions, while cotransfection of WNT5A DNA enabled sufficient protein production to increase the already strong BRET signal (Fig. 4B). It is unclear whether recombinant WNT5A protein was administered at concentrations insufficient to increase the BRET signal, the kinetics of productive BRET interactions and FZD TMD versus CRD interactions affect these observations, or acute versus chronic stimulation (protein vs. plasmid) with WNT5A can build up various effects on $\mathrm{FZD}_{4}$. It is also possible that these differences in $\mathrm{FZD}_{4}$ dimerization between recombinant WNT5A or transfected WNT5A are due to differential packaging and binding to carrier proteins. To investigate whether WNT5A-mediated stimulation of $\mathrm{FZD}_{4}-\mathrm{FZD}_{4}$ interactions was dependent on palmitoleoyl and CRD interactions, we individually mutated key hydrophobic residues in the lipid-binding groove. Each of these mutants prevented any WNT5A-dependent increase in the BRET ratio, suggesting that Wnts are unable to mediate $\mathrm{FZD}_{4}$ interactions when the integrity of the lipid-binding groove is not maintained. Interestingly, each of these mutants increased the FZD-FZD interactions in the absence of Wnt and, surprisingly, in the case of L85A, may even decrease the interactions upon addition of Wnt (Fig. 4C).

To determine whether WNT5A affects higher-order $\mathrm{FZD}_{4}$ interactions, we took a three-hybrid BRET approach using Rlu with split-YFP-tagged FZD constructs (Fig. 5A). We show that $\mathrm{FZD}_{4}$ does not oligomerize independently of WNT5A, consistent with previous observations (Ke et al. 2013). However, we observed a dose-dependent increase in $\mathrm{FZD}_{4}$ oligomerization in response to the addition of WNT5A protein and a strong increase in response to DNA cotransfection (Fig. 5B). Mutation of palmitoleoyl-binding residues in the CRD increased WNT5A-independent $\mathrm{FZD}_{4}$ oligomerization to varying levels, but, in every case, any effect of WNT5A on increasing oligomerization was abolished (Fig. 5C).

\section{Palmitoleoyl-binding residues are required for WNT5A signaling}

Since mutations in $\mathrm{FZD}_{4}$ palmitoleoyl-binding residues abolished the effect of WNT5A on $\mathrm{FZD}_{4}$ oligomerization, we next investigated whether these mutations also affect signaling in luciferase assays with Wnt/ $\beta$-catenin or c-Jun/ AP-1 pathway readouts. Since WNT5A signals predominantly through receptor tyrosine kinase-like orphan receptor 2 (ROR2), we cloned a chimeric ROR2:LRP5 coreceptor in which the extracellular domain of ROR2 was fused to the TMD and intracellular domain of LRP5 (Grumolato et al. 2010). In a TCF-luciferase assay using this ROR2:LRP5 chimeric receptor, we showed that hydrophobic mutations in the $\mathrm{FZD}_{4}$ palmitoleoyl-binding groove inhibit Wnt-mediated signaling (Fig. 6A, F82A, L85A, L132A, and F135A). We further validated these results with a c-Jun/AP-1 pathway readout in which phorbol 12-myristate 13-acetate (PMA) was used to activate protein kinase $\mathrm{C}(\mathrm{PKC})$ to stimulate WNT5A signaling to levels sufficient for an AP-1 luciferase reporter gene assay. Although PMA also activates AP-1 independently of Wnts (Chen et al. 2003), transfected FZD $_{4}$ further increased the luciferase signal threefold (Supplemental Fig. S6). We observed significant decreases in signaling in F82A and L85A FZD 4 mutants relative to wild type (Fig. $6 \mathrm{~B})$. While this assay is less sensitive compared with the TCF-luciferase assay, to our knowledge, it is the only reporter gene assay that measures $\mathrm{Wnt} / \beta$-catenin-independent WNT5A signaling. Furthermore, we demonstrated that the same mutations that abolish the effect of WNT5A on $\mathrm{FZD}_{4}$ oligomerization also inhibit signaling. Together, we provided evidence that integrity of the 


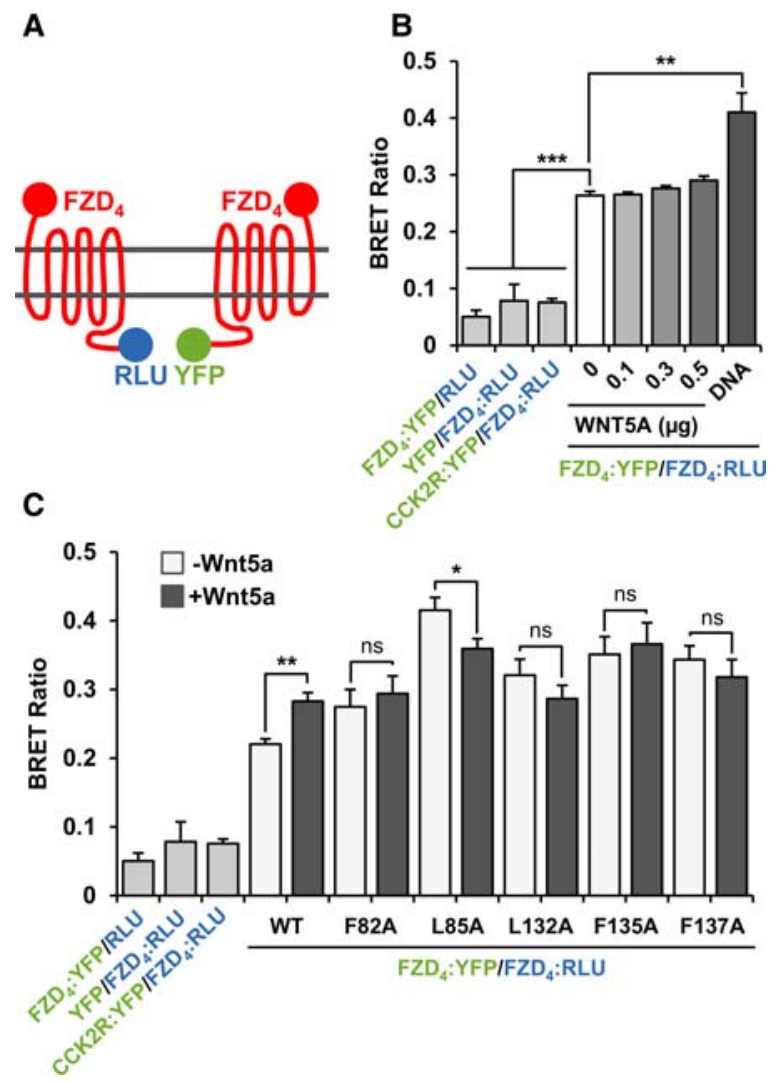

Figure 4. WNT5A increases $\mathrm{FZD}_{4}$ homodimer interactions through palmitoleoyl-binding residues. $(A)$ Cartoon of two-hybrid BRET assay design in which $\mathrm{FZD}_{4}$ :Rlu and $\mathrm{FZD}_{4}$ :YFP C-terminal fluorophore fusion constructs were cotransfected. $(B)$ Titration of WNT5A recombinant protein (in micrograms) or cotransfection of WNT5A ( $1 \mu \mathrm{g}$ of DNA plasmid) with FZD $_{4}$ BRET constructs shows that $\mathrm{FZD}_{4}$ autodimerizes in the absence of Wnt and that Wnt further increases $\mathrm{FZD}_{4}-\mathrm{FZD}_{4}$ interactions. Recombinant protein was added $15 \mathrm{~min}$ before analysis, and plasmid was added $24 \mathrm{~h}$ before analysis. $(C)$ WNT5A cannot increase $\mathrm{FZD}_{4}-\mathrm{FZD}_{4}$ interactions when hydrophobic palmitoleoyl-binding $\mathrm{FZD}_{4}$ residues are replaced with alanine residues. $\mathrm{FZD}_{4}$ expression plasmids were cotransfected with or without WNT5A expression plasmid; both YFP and Rlu-tagged plasmids contained $\mathrm{FZD}_{4}$ mutations as indicated. $\left(^{*}\right) P<0.05$; $\left(^{* *}\right) P<0.01$; $\left(^{* * *}\right) P<0.001$; (ns) not significant. $n \geq 6$. Error bars indicate SEM for all graphs.

palmitoleoyl-binding groove is required for WNT5A-dependent $\mathrm{FZD}_{4}$ oligomerization and signaling.

\section{Discussion}

The dynamics of FZD receptors are only beginning to be understood. The architecture of class FZD GPCRs seems to be constructed for oligomerization, and the formation of intracellular scaffolds seems to be constructed for signaling. Like many GPCRs, FZDs appear to autodimerize efficiently through their TMDs, which then may enhance lower-affinity CRD dimerization. However, we showed that the cue for FZD activation is not receptor dimerization but higher-order interactions. Our three-hybrid
BRET assay shows that WNT5A can induce $\mathrm{FZD}_{4}$ oligomerization in the membranes of live cells. Since WNT5A and WNT8A strongly enhance the two-hybrid BRET signal of the membrane-tethered CRD in the absence of the $\mathrm{FZD}_{4} \mathrm{TMD}$, Wnt-responsive oligomerization likely occurs through Wnt binding to its primary FZDbinding site, the CRD. Thus, a dynamic balance exists between FZD transmembrane autodimerization and Wntinduced CRD interactions, and these interactions may function independently of one another (Fig. 7A).

The CRD seems particularly well suited as a "hub" domain for oligomerization, since it is globular, sufficiently independent of the transmembrane bundle to enable oligomerization (Supplemental Fig. S5B), and can bind Wnts with high affinity. The remarkable sequence and structural conservation of the CRD among FZDs suggests that this mechanism of oligomerization is shared among

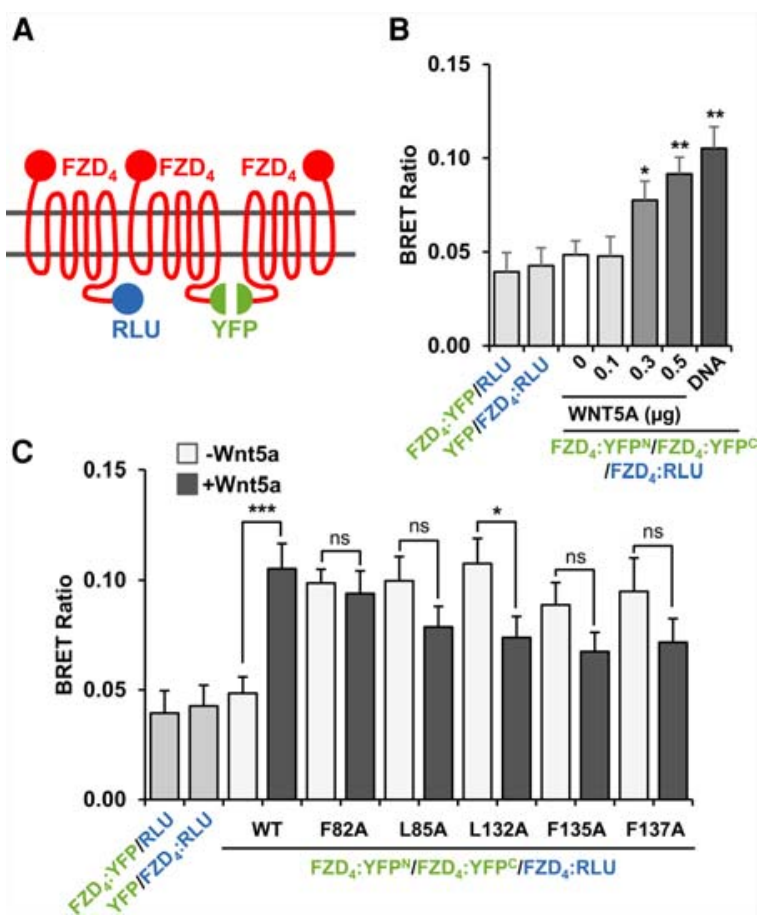

Figure 5. WNT5A induces $\mathrm{FZD}_{4}$ oligomerization through palmitoleoyl-binding residues. $(A)$ Cartoon of three-hybrid BRET assay design in which $\mathrm{FZD}_{4}$ :Rlu and split $\mathrm{FZD}_{4}$ :YFP C-terminal fluorophore fusion constructs were cotransfected. (B) Titration of WNT5A recombinant protein (in micrograms) or cotransfection of WNT5A ( $1 \mu \mathrm{g}$ of DNA plasmid) with FZD $_{4}$ BRET constructs shows that WNT5A induces $\mathrm{FZD}_{4}$ oligomerization in a dose-dependent manner and that $\mathrm{FZD}_{4}$ does not auto-oligomerize. Recombinant protein was added $15 \mathrm{~min}$ before analysis, and plasmid was added $24 \mathrm{~h}$ before analysis. (C) WNT5A cannot induce $\mathrm{FZD}_{4}$ oligomerization when alanine residues are substituted for hydrophobic palmitoleoyl-binding $\mathrm{FZD}_{4}$ residues. $\mathrm{FZD}_{4}$ expression plasmids were cotransfected with or without WNT5A expression plasmid; both $\mathrm{YFP}^{\mathrm{N}} / \mathrm{YFP}^{\mathrm{C}}$ and Rlu-tagged plasmids contained $\mathrm{FZD}_{4}$ mutations as indicated. $\left({ }^{*}\right) P<0.05$; $\left.\left.{ }^{(* *}\right) P<0.01 ;{ }^{* * *}\right) P<0.001$; (ns) not significant. $n \geq 6$. Error bars indicate SEM for all graphs. 

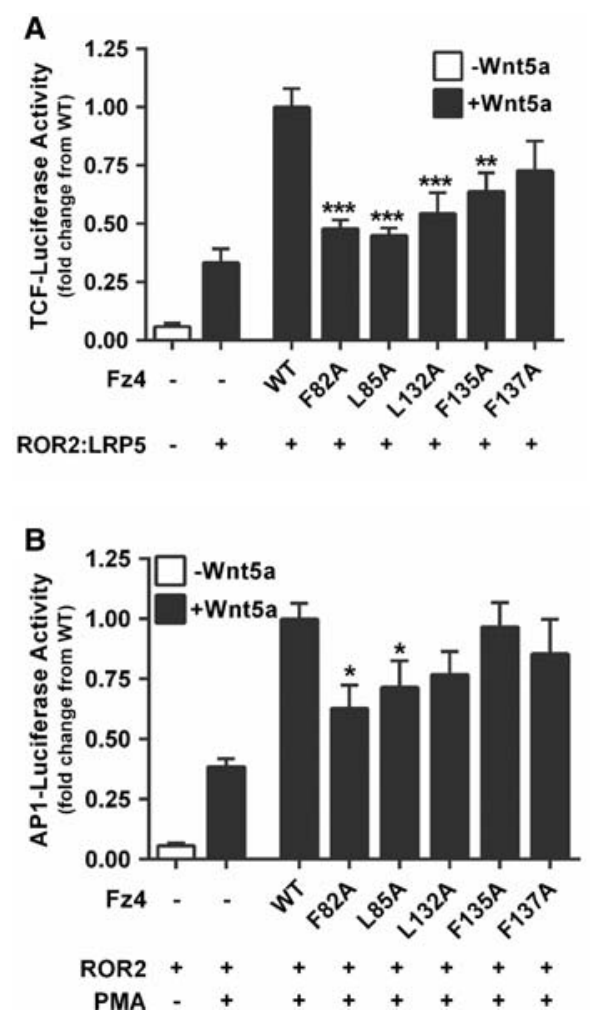

Figure 6. $\mathrm{FZD}_{4}$ palmitoleoyl-binding residues are required for WNT5A signaling. (A) TCF-luciferase reporter gene assay performed with cotransfection of WNT5A, an ROR2:LRP5 chimeric coreceptor (ROR2 extracellular domain fused to the LRP5 TMD and intracellular domain), and $\mathrm{FZD}_{4}$ palmitoleoyl-binding groove mutants. $n=4$. Error bars indicate SEM. $(B)$ AP1-luciferase reporter gene assay performed with cotransfection of WNT5A, ROR2 coreceptor, and $\mathrm{FZD}_{4}$ palmitoleoyl-binding groove mutants followed by PMA treatment. $\left(^{*}\right) P<0.05$; $\left.{ }^{* *}\right) P<0.01 ;\left(^{* * *}\right) P<$ 0.001. $n=3$. Error bars indicate SEM for all graphs.

family members and is essential for FZD regulation (Fig. 7B,C). While this work was in revision, Nile et al. (2017) published the structures of $\mathrm{FZD}_{5}$ and $\mathrm{FZD}_{7}$ CRDs bound to unsaturated fatty acids, which revealed dimeric CRD arrangements with each fatty acid occupying the large continuous hydrophobic pockets of a CRD dimer, strikingly similar to what we observed in $\mathrm{FZD}_{4}$. It appears that unsaturated fatty acylation of Wnt can mediate FZD CRD dimerization with a 2:1 FZD:Wnt stoichiometry, which was biochemically validated by the ability of unsaturated fatty acids to induce human $\mathrm{FZD}_{7} \mathrm{CRD}$ dimerization in a reconstituted system (Nile et al. 2017). This report is consistent with the 2:1 stoichiometry of the $\mathrm{FZD}_{4} \mathrm{CRD}$ and palmitoleic acid as observed in our structure and also supports earlier findings that sFRP1 binds to Drosophila Wingless $(\mathrm{Wg})$ with 2:1 stoichiometry (Uren et al. 2000). In summary, these reports suggest that Wnts generally may associate with two CRDs.

The mutations in the palmitoleoyl-binding groove of the $\mathrm{FZD}_{4} \mathrm{CRD}$ provide valuable insights into the regulation of FZD activation by CRDs. We observed that alanine substitutions for single hydrophobic residues in the pal- mitoleoyl-binding groove increased $\mathrm{FZD}_{4}$ oligomerization in the absence of WNT5A, whereas the presence of WNT5A no longer stimulated-and may actually reduce -oligomerization. The mechanism behind this observation remains obscure but perhaps may be explained by altered positioning of Wnt on FZD due to the destabilization of the acyl-binding site. It also might suggest that the CRD represses basal FZD oligomerization to ensure that oligomerization is strictly Wnt-dependent. Interestingly, it was reported that complete deletion of the FZD CRD still allows Wnt signal activation (Chen et al. 2004), at least under overexpression conditions (Povelones and Nusse 2005), while mutations in the CRD disrupt signalosome assembly and act as negative regulators of Wnt signal activation. The observation that CRD-independent signaling is still regulated by Wnts suggests that non-CRDbinding events regulate Wnt pathway activation as well. These CRD-independent mechanisms of receptor activation might depend on the CRD-to-transmembrane linker, a long and apparently flexible string of unconserved residues, which are required for activation in the case of Smoothened (Byrne et al. 2016) and harbor loss-of-function missense mutations in $\mathrm{FZD}_{4}$-linked genetic diseases (Toomes et al. 2004; Nikopoulos et al. 2010). These linker domains might orchestrate Wnt/FZD specificity beyond the CRD and harbor secondary Wnt-binding sites.

While the effects of palmitoleoyl-binding groove mutations were consistent throughout our experiments, they could be due to the disruption of palmitoleic acid-
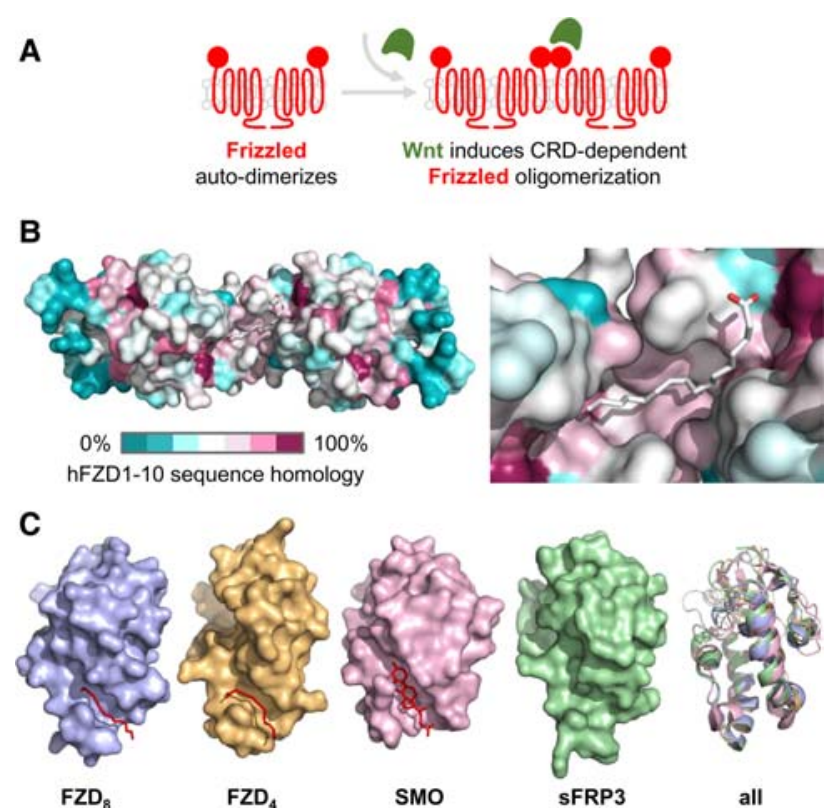

Figure 7. The palmitoleoyl-binding groove in FZD CRDs is highly conserved. (A) Proposed model in which FZD autodimerizes, and WNT5A induces FZD oligomerization by mediating CRD dimerization through end-to-end palmitoleoyl-binding grooves. (B) Sequence conservation of $\mathrm{FZD}_{4}$ CRD palmitoleoylbinding groove residues among human FZD family members. (C) Structural conservation of FZD CRDs revealing lipid- and sterol-binding compatibility. 
dependent CRD oligomerization or the disruption of all WNT5A-FZD 4 interactions (note that mini-Wnt proteins lacking palmitoylation can still bind $\mathrm{FZD}_{4}$ in vitro through the "index finger" interaction with lower affinity [Janda et al. 2012] that may or may not be compensated for by overexpression in cells). The structure of the palmitoleic acid-bound CRD therefore presents a plausible mechanism for how Wnts can induce FZD oligomerization, but technically challenging further experiments are necessary to directly demonstrate a link between palmitoleoyl binding and FZD oligomerization. In an alternative scenario, the overhanging hydrophobic chain of the palmitoleoyl group could be buried in the transmembrane bundle, similar to the cholesterol group in the recent Smoothened structure. In this structure, the sterol-binding groove is solvent-protected by the CRD-to-transmembrane linker and ECL3 (Supplemental Fig. S5A). However, we noticed that Smoothened is unlike FZDs in this regard, as FZDs have a longer linker and a shorter ECL3 (Supplemental Fig. S5B,C), suggesting higher flexibility and more independence between the CRD and the transmembrane bundle. We further reasoned that if CRD activation at the ECL3 or linker were indeed a basic mechanism of FZD activation, it would be conserved across all family members, which is not the case (Supplemental Fig. S5C).

It is intriguing that the palmitoleic acid-bound CRD forms a tetramer, although no biochemical evidence exists for this higher-order structure. In fact, many of the interactions in the FZD and Wnt signalosome have not been discovered or recapitulated in biochemical assays due to the weak binding energies between these surfaces. However, structural data suggest that these interactions may indeed exist. We noticed that no published crystal structures of FZD or FZD-related CRDs are monomeric (PDB $\mathrm{FZD}_{4}$ : 5BPB, 5BPQ, and 5CM4; FZD 8 : 1IJY; sFRP3: 1IJX; and MuSK: $3 \mathrm{HKL}$ ). The interaction interfaces in these structures appear to be thermodynamically stable and, in the case of $\mathrm{FZD}_{4}$, occur in multiple crystal forms that piece together to form a tetrameric assembly /Chang et al. 2015; Shen et al. 2015). It is challenging to study Wnt-FZD interactions biochemically due to the lipophilic nature of Wnt acyl moieties. Furthermore, Wnts have multiple binding sites for FZD that contribute variously to initial binding events and, presumably, higher-order binding events, all of which complicate mutational approaches to studying these interactions. Fluorescencebased approaches permit the study of these weak interactions in the membrane environment of live cells and circumvent many obstacles faced by traditional biochemical assays. Indeed, the concept of signalosomes centers on high concentrations of weakly interacting proteins that collectively can assemble complexes and exert signaling consequences when brought into close proximity.

Tetramers of FZD CRDs would bring dimerized TMDs into closer proximity and create an intracellular scaffold for Dishevelled binding. This scaffold might promote the phase shift toward Dishevelled/Axin copolymerization and intracellular Wnt signalosome assembly. Dishevelled DEP domains associate as inactive monomers at the intracellular FZD transmembrane core but have been shown recently to dimerize in response to Wnt signals, and, intriguingly, these dimers crystallize as tetramers with monomer widths analogous to the width of a GPCR transmembrane bundle (PDB 5SUY) (Gammons et al. 2016a). Furthermore, higher-order FZD oligomerization might be mediated by LRP5/6 dimers upon Wnt binding (Cong et al. 2004; Shahi et al. 2012; Chen et al. 2014). Thus, in theory, two or more Wnts could bind a single LRP5/6 dimer to bring FZD tetramers into close proximity, extend intracellular FZD rafts, stabilize a number of Dishevelled DEP domain dimers or tetramers, and catalyze large-scale Dishevelled DIX polymerization and the assembly of Dishevelled signalosomes. These hypotheses raise many questions, such as the significance of LRP5/6FZD interactions in the absence of Wnt, the selectivity of Wnts for distinct LRP5/6-binding sites, the conformational changes induced in LRP5/6 dimers in response to Wnt binding, and the orientation of LRP5/6-FZD complexes in active and inactive complexes.

The emerging concept of FZD signalosome assembly is fundamental to therapeutic targeting of the Wnt pathway. For example, inhibitors that bind the hydrophobic lipidbinding groove of FZD CRDs might obstruct FZD signalosome assembly and block signaling activity to a degree similar to that of palmitoleoyl-binding residue mutants. Larger inhibitors such as antibodies might also obstruct oligomerization by steric interference. The interfaces between FZD and LRP5/6 are yet unknown and may be regulated by specific conformations dependent on receptor oligomerization and Wnt binding. Finally, it is possible that additional Wnt-binding surfaces exist beyond the CRD within the Wnt receptor signalosome, and these might be targeted with high specificity for certain Wnt/ FZD pairings.

In summary, our results demonstrate that WNT induces FZD CRD dimerization through binding of one WNT palmitoleoyl group to the lipid-binding grooves of two CRDs. We also provide a structural mechanism for WNT-induced FZD oligomerization through the binding and stabilization of CRD dimers in FZDs with pre-existing TMD interactions. In subsequent studies, it will be important to further explore the proposed oligomerization mechanism, the interdependence of intermolecular and intramolecular TMD and CRD interactions, and the significance of these interactions in orchestrating WNT signalosome assembly.

\section{Materials and methods}

\section{DNA plasmids}

For BRET assays, the $\mathrm{FZD}_{4} \mathrm{CRD}$ was fused at the $\mathrm{C}$ terminus to an unrelated single-pass TMD from CD8 and tagged with Rlu, YFP, YFP ${ }^{N}$, or YFP ${ }^{\mathrm{C}}$ to create FZD ${ }_{4}^{\mathrm{CRD}}: \mathrm{TM}: \mathrm{Rlu}, \mathrm{FZD}_{4}^{\mathrm{CRD}}: \mathrm{TM}$ : YFP, FZD ${ }_{4}^{C R D}: T_{M}: Y^{N}$, and $\mathrm{FZD}_{4}^{\mathrm{CRD}}$ :TM:YFP ${ }^{\mathrm{C}}$ expression constructs in a pcDNA3.1 vector. The expression plasmids harboring full-length $\mathrm{FZD}_{4}$ tagged with Rlu, YFP, YFP ${ }^{\mathrm{N}}$, or $\mathrm{YFP}^{\mathrm{C}}$ have been described previously (Ke et al. 2013). WNT5A and WNT8A expression plasmids were purchased from Addgene. $\mathrm{FZD}_{4}$ receptor lipid-binding groove mutants (F82A, L85A, L132A, F135A, and F137) were generated by PCR-based site-directed mutagenesis 
using Phusion enzyme. For protein expression, the human $\mathrm{FZD}_{4}$ CRD was cloned in fusion with human IgG1 Fc and His6 tandem tags to create the $\mathrm{FZD}_{4}$-CRD-FcH6 fusion construct in a tetracycline-inducible mammalian expression vector as described previously (Shen et al. 2015). This construct also contains a murine Igא leader sequence at the $\mathrm{N}$ terminus for protein secretion and a thrombin cleavage site between the FZD 4 CRD and Fc for tag removal. All DNA constructs were verified by automated DNA sequencing.

Cell-based luciferase assay

HEK293 cells were cultured in DMEM (Gibco) with 5\% fetal bovine serum (FBS). Cells were plated in a 24 -well plate $24 \mathrm{~h}$ prior to transfection. Cells were transfected at $50 \%$ confluency with the indicated plasmids using Lipofectamine 2000 (Invitrogen). For TCF-luciferase assay, cells were also transfected with a TCF-luciferase reporter gene plasmid, and the cells were harvested 24 $\mathrm{h}$ later. For the AP-1-luciferase assay, cells were also transfected with a AP-1-luciferase reporter gene plasmid; $24 \mathrm{~h}$ later, PMA was added to each well for a final concentration of $100 \mathrm{nM}$, and, 24 additional hours later, the cells were harvested. Cells were lysed with $80 \mu \mathrm{L}$ of passive lysis buffer (Promega) for $20 \mathrm{~min}$ at room temperature, and the firefly luciferase activities were measured using an Envision luminometer (PerkinElmer) with the dual-luciferase assay kit (Promega).

Protein expression and purification

For protein expression and purification, a stable HEK293S cell line expressing the $\mathrm{FZD}_{4}$-CRD-FcH6 fusion protein was established as described previously (Chen et al. 2013; Shen et al. 2015). The stable cell line was cultured in CDM4HEK293 medium (HyClone) until the cell density reached $\sim 2 \times 10^{6}$ cells per milliliter. Protein expression was induced by the addition of doxycycline to a final concentration of $0.25 \mu \mathrm{g} / \mathrm{mL}$. After $3 \mathrm{~d}$ of induction, the medium supernatant was harvested by centrifugation at $10,800 \mathrm{~g}$ for $20 \mathrm{~min}$ to remove cells and dialyzed against buffer A (20 mM Tris at $\mathrm{pH} 8.0,0.15 \mathrm{M} \mathrm{NaCl}, 10 \%$ glycerol) overnight before purifying the $\mathrm{FZD}_{4}$-CRD-FcH6 protein by a $50-\mathrm{mL}$ Ni-chelating HiLoad Sepharose column (GE Healthcare). Peak elution fractions were pooled and subjected to thrombin digestion at a 1:500 thrombin:protein mass ratio while dialyzing against buffer A overnight at $4{ }^{\circ} \mathrm{C}$. The digestion product was loaded onto a $5-\mathrm{mL}$ Ni-chelating HiLoad Sepharose column (GE Healthcare) to remove the FcH6 tag. The flowthrough was collected and further purified by $120 \mathrm{~mL}$ of HiLoad 16/60 Superdex-200 gel filtration.

\section{Crystallization and structure determination}

The FZD ${ }_{4}$ CRD protein was mixed with palmitoleic acid (Sigma) at a molar ratio of $1: 1.5$ and incubated for $2-3 \mathrm{~h}$ at $4^{\circ} \mathrm{C}$ before concentrating to $\sim 8 \mathrm{mg} / \mathrm{mL}$ for crystallization trials using the Phoenix crystallization robot and commercial screens. Crystals were grown at $20^{\circ} \mathrm{C}$ by the hanging drop vapor diffusion method using an equal volume of protein sample and crystallization solution (0.1 M citric acid at $\mathrm{pH} 3.5,28 \%[\mathrm{w} / \mathrm{v}]$ polyethylene glycol 8000). Single rod-shaped crystals with a longest dimension of $0.15 \mathrm{~mm}$ were soaked briefly in crystallization solution plus $22 \%(\mathrm{v} / \mathrm{v})$ ethylene glycerol before being frozen in liquid nitrogen. $\mathrm{FZD}_{4}$ CRD with palmitoleic acid complex crystal diffraction data were collected at Sector 21 (Life Sciences Collaborative Access Team) of the Advanced Photon Source synchrotron using a single crystal under a liquid nitrogen stream. The diffraction data were processed using XDS (Kabsch 2010), combined using Pointless
(Winn et al. 2011), and merged using Scala from the CCP4 suite (Winn et al. 2011). The complex structure was determined by molecular replacement with the program PHASER (McCoy et al. 2007) using the crystal structures of the $\mathrm{FZD}_{4} \mathrm{CRD}$ (PDB $5 \mathrm{CM} 4)$ as the initial search model. Crystallographic refinements were carried out with REFMAC5 (Murshudov et al. 2011) and PHENIX (Adams et al. 2010), and model building was carried out using Coot. The final refinement statistics are summarized in Table 1. The $\mathrm{FZD}_{4}$ CRD structure was deposited into the PDB with code 5 UWG.

\section{BRET studies}

BRET was performed using transfected COS-1 cells that expressed tagged receptor constructs that had been sequence-verified (Harikumar et al. 2007). Equal amounts of all constructs in identical expression vectors were cotransfected. Cells were harvested $48 \mathrm{~h}$ after transfection. When recombinant WNT5A protein was used, cells were harvested $15 \mathrm{~min}$ after the addition of WNT5A protein; thus, WNT5A protein was administered at 47 h $45 \mathrm{~min}$ after transfection. The cells $(\sim 25,000$ cells per well $)$ were collected for bioluminescence and fluorescence measurements in 96-well white Optiplates, which were performed as

Table 1. X-ray data collection and refinement statistics for the $\mathrm{FZD}_{4} \mathrm{CRD}$ and palmitoleic acid complex structure

$\mathrm{FZD}_{4} \mathrm{CRD}+$ palmitoleic

$\operatorname{acid}^{\mathrm{a}}$

\begin{tabular}{|c|c|}
\hline \multicolumn{2}{|l|}{ Data collection } \\
\hline Space group & $\mathrm{C} 222_{1}$ \\
\hline \multicolumn{2}{|l|}{ Cell dimensions } \\
\hline$a, b, c$ & $103.5 \AA ̊, 109.4 \AA ̊, 76.8 \AA$ \\
\hline$\alpha, \beta, \gamma$ & $90^{\circ}, 90^{\circ}, 90^{\circ}$ \\
\hline Wavelength & 0.9786 \\
\hline Resolution & $50 \AA-2.56 \AA(2.67 \AA-2.56 \AA)$ \\
\hline$R_{\text {sym }}$ or $R_{\text {merge }}$ & $0.041(1.0)^{\mathrm{b}}$ \\
\hline$I / \sigma I$ & $25.3(2.0)^{\mathrm{b}}$ \\
\hline Completeness & $99.8 \%(100.0 \%)^{\mathrm{b}}$ \\
\hline Redundancy & $7.3(7.5)^{\mathrm{b}}$ \\
\hline \multicolumn{2}{|l|}{ Refinement } \\
\hline Resolution & $50 \AA-2.56 \AA$ \\
\hline $\begin{array}{l}\text { Number of reflections } \\
\text { (test set) }\end{array}$ & $14334(744)$ \\
\hline$R_{\text {work }} / R_{\text {free }}$ & $0.243 / 0.266$ \\
\hline $\begin{array}{l}\text { Number of molecules per } \\
\text { asymmetric unit }\end{array}$ & 2 \\
\hline \multicolumn{2}{|l|}{ Number of atoms } \\
\hline Protein & 1745 \\
\hline Palmitoleic acid & 18 \\
\hline Water & 6 \\
\hline \multicolumn{2}{|l|}{$B$-factors } \\
\hline Protein & 99.3 \\
\hline Palmitoleic acid & 82.2 \\
\hline Water & 103.0 \\
\hline \multicolumn{2}{|l|}{ Root-mean-square deviations } \\
\hline Bond lengths & $0.008 \AA$ \\
\hline Bond angles & $1.14^{\circ}$ \\
\hline Ramachandran favored & $96.41 \%$ \\
\hline Ramachandran allowed & $3.59 \%$ \\
\hline Ramachandran outliers & $0.0 \%$ \\
\hline
\end{tabular}

${ }^{a}$ The X-ray diffraction data were obtained from a single crystal.

${ }^{b}$ Values in parentheses are for the highest-resolution shell. 
described previously (Harikumar et al. 2007). BRET assays were initiated by mixing $5 \mu \mathrm{M}$ coelenterazine $h$ (Rlu-specific substrate) with the cell suspension. Luminescence and fluorescence signals were collected immediately using a 2103 Envision fluorescence plate reader configured with the $<700$-nm mirror and dual emission filter sets for luminescence $(460 \mathrm{~nm}$; bandwidth $25 \mathrm{~nm}$ ) and fluorescence ( $535 \mathrm{~nm}$; bandwidth $25 \mathrm{~nm}$ ). YFP fluorescence was acquired by exciting the samples at $480 \mathrm{~nm}$. Background BRET signals for the experimental conditions were measured using a soluble complementary donor or acceptor or a tagged structurally unrelated receptor. Absolute BRET ratios were calculated based on the ratio of YFP and Rlu emission signals, as described previously (Harikumar et al. 2007).

\section{Acknowledgments}

We thank Michelle Martin for administrative support, and staff members of the Life Science Collaborative Access Team (ID-21) of the Advanced Photon Source (APS) for assistance in data collection at the beam lines of Sector 21, which is in part funded by the Michigan Economic Development Corporation and the Michigan Technology Tri-Corridor (grant 085P1000817). Use of the APS was supported by the Office of Science of the US Department of Energy under contract number DE-AC02-06CH11357. We thank Ms. M-L Augustine for her excellent technical assistance with cell cultures. Z.J.D., J.K., K.G.H., and X.G. performed experiments; Z.J.D., J.K., K.G.H., L.J.M., H.E.X., and K.M. designed experiments and analyzed data, J.K., K.G.H., B.O.W., W.X., H.E.X., and K.M. conceived the project; and Z.J.D., H.E.X., and K.M. wrote the manuscript with contributions from all authors.

\section{References}

Adams PD, Afonine PV, Bunkoczi G, Chen VB, Davis IW, Echols N, Headd JJ, Hung LW, Kapral GJ, Grosse-Kunstleve RW, et al. 2010. PHENIX: a comprehensive Python-based system for macromolecular structure solution. Acta Crystallogr D Biol Crystallogr 66: 213-221.

Anastas JN, Moon RT. 2013. WNT signalling pathways as therapeutic targets in cancer. Nat Rev Cancer 13: 11-26.

Bazan JF, Janda CY, Garcia KC. 2012. Structural architecture and functional evolution of Wnts. Dev Cell 23: 227-232.

Bilic J, Huang YL, Davidson G, Zimmermann T, Cruciat CM, Bienz M, Niehrs C. 2007. Wnt induces LRP6 signalosomes and promotes dishevelled-dependent LRP6 phosphorylation. Science 316: 1619-1622.

Byrne EF, Sircar R, Miller PS, Hedger G, Luchetti G, Nachtergaele S, Tully MD, Mydock-McGrane L, Covey DF, Rambo RP, et al. 2016. Structural basis of Smoothened regulation by its extracellular domains. Nature 535: 517-522.

Chang TH, Hsieh FL, Zebisch M, Harlos K, Elegheert J, Jones EY. 2015. Structure and functional properties of Norrin mimic Wnt for signalling with Frizzled4, Lrp5/6, and proteoglycan. Elife 4: e06554.

Chen W, ten Berge D, Brown J, Ahn S, Hu LA, Miller WE, Caron MG, Barak LS, Nusse R, Lefkowitz RJ. 2003. Dishevelled 2 recruits $\beta$-arrestin 2 to mediate Wnt5A-stimulated endocytosis of Frizzled 4. Science 301: 1391-1394.

Chen CM, Strapps W, Tomlinson A, Struhl G. 2004. Evidence that the cysteine-rich domain of Drosophila Frizzled family receptors is dispensable for transducing Wingless. Proc Natl Acad Sci 101: 15961-15966.

Chen S, Bubeck D, MacDonald BT, Liang WX, Mao JH, Malinauskas T, Llorca O, Aricescu AR, Siebold C, He X, et al. 2011.
Structural and functional studies of LRP6 ectodomain reveal a platform for Wnt signaling. Dev Cell 21: 848-861.

Chen C, Ke J, Zhou XE, Yi W, Brunzelle JS, Li J, Yong EL, Xu HE, Melcher K. 2013. Structural basis for molecular recognition of folic acid by folate receptors. Nature 500: 486-489.

Chen J, Yan H, Ren DN, Yin Y, Li Z, He Q, Wo D, Ho MS, Chen Y, Liu Z, et al. 2014. LRP6 dimerization through its LDLR domain is required for robust canonical Wnt pathway activation. Cell Signal 26: 1068-1074.

Cheng Z, Biechele T, Wei Z, Morrone S, Moon RT, Wang L, Xu W. 2011. Crystal structures of the extracellular domain of LRP6 and its complex with DKK1. Nat Struct Mol Biol 18: 1204-1210.

Clevers H. 2006. Wnt/ $\beta$-catenin signaling in development and disease. Cell 127: 469-480.

Cong F, Schweizer L, Varmus H. 2004. Wnt signals across the plasma membrane to activate the $\beta$-catenin pathway by forming oligomers containing its receptors, Frizzled and LRP. Development 131: 5103-5115.

Dann CE, Hsieh JC, Rattner A, Sharma D, Nathans J, Leahy DJ. 2001. Insights into Wnt binding and signalling from the structures of two Frizzled cysteine-rich domains. Nature 412: 86-90.

Feng Q, Gao N. 2015. Keeping Wnt signalosome in check by vesicular traffic. J Cell Physiol 230: 1170-1180.

Ferre S, Baler R, Bouvier M, Caron MG, Devi LA, Durroux T, Fuxe K, George SR, Javitch JA, Lohse MJ, et al. 2009. Building a new conceptual framework for receptor heteromers. Nat Chem Biol 5: 131-134.

Fiedler M, Mendoza-Topaz C, Rutherford TJ, Mieszczanek J, Bienz M. 2011. Dishevelled interacts with the DIX domain polymerization interface of Axin to interfere with its function in down-regulating $\beta$-catenin. Proc Natl Acad Sci 108: 1937-1942.

Gammons MV, Renko M, Johnson CM, Rutherford TJ, Bienz M. 2016a. Wnt signalosome assembly by DEP domain swapping of Dishevelled. Mol Cell 64: 92-104.

Gammons MV, Rutherford TJ, Steinhart Z, Angers S, Bienz M. 2016b. Essential role of the Dishevelled DEP domain in a Wnt-dependent human-cell-based complementation assay. I Cell Sci 129: 3892-3902.

Gao X, Hannoush RN. 2014. Single-cell imaging of Wnt palmitoylation by the acyltransferase porcupine. Nat Chem Biol 10: 61-68.

Grumolato L, Liu G, Mong P, Mudbhary R, Biswas R, Arroyave R, Vijayakumar S, Economides AN, Aaronson SA. 2010. Canonical and noncanonical Wnts use a common mechanism to activate completely unrelated coreceptors. Genes Dev 24: 2517-2530.

Hannoush RN, Arenas-Ramirez N. 2009. Imaging the lipidome: $\omega$-alkynyl fatty acids for detection and cellular visualization of lipid-modified proteins. ACS Chem Biol 4: 581-587.

Harikumar KG, Pinon DI, Miller LJ. 2007. Transmembrane segment IV contributes a functionally important interface for oligomerization of the Class II G protein-coupled secretin receptor. J Biol Chem 282: 30363-30372.

He X, Saint-Jeannet JP, Wang Y, Nathans J, Dawid I, Varmus H. 1997. A member of the Frizzled protein family mediating axis induction by Wnt-5A. Science 275: 1652-1654.

He X, Semenov M, Tamai K, Zeng X. 2004. LDL receptor-related proteins 5 and 6 in $\mathrm{Wnt} / \beta$-catenin signaling: arrows point the way. Development 131: 1663-1677.

Huang YL, Anvarian Z, Doderlein G, Acebron SP, Niehrs C. 2015. Maternal Wnt/STOP signaling promotes cell division during 
early Xenopus embryogenesis. Proc Natl Acad Sci 112: 5732-5737.

Janda CY, Waghray D, Levin AM, Thomas C, Garcia KC. 2012. Structural basis of Wnt recognition by Frizzled. Science 337: 59-64.

Kabsch W. 2010. Xds. Acta Crystallogr D Biol Crystallogr 66: $125-132$.

Kakugawa S, Langton PF, Zebisch M, Howell SA, Chang TH, Liu Y, Feizi T, Bineva G, O’Reilly N, Snijders AP, et al. 2015. Notum deacylates Wnt proteins to suppress signalling activity. Nature 519: 187-192.

Ke J, Harikumar KG, Erice C, Chen C, Gu X, Wang L, Parker N, Cheng Z, Xu W, Williams BO, et al. 2013. Structure and function of Norrin in assembly and activation of a Frizzled 4-Lrp5/ 6 complex. Genes Dev 27: 2305-2319.

Madrzak J, Fiedler M, Johnson CM, Ewan R, Knebel A, Bienz M, Chin JW. 2015. Ubiquitination of the Dishevelled DIX domain blocks its head-to-tail polymerization. Nat Commun 6: 6718.

Matoba K, Mihara E, Tamura-Kawakami K, Miyazaki N, Maeda S, Hirai H, Thompson S, Iwasaki K, Takagi J. 2017. Conformational freedom of the LRP6 ectodomain is regulated by N-glycosylation and the binding of the Wnt antagonist Dkk1. Cell Rep 18: 32-40.

McCoy AJ, Grosse-Kunstleve RW, Adams PD, Winn MD, Storoni LC, Read RJ. 2007. Phaser crystallographic software. I Appl Crystallogr 40: 658-674.

Mikels AJ, Nusse R. 2006. Purified Wnt5a protein activates or inhibits $\beta$-catenin-TCF signaling depending on receptor context. PLOS Biol 4: el15.

Murshudov GN, Skubak P, Lebedev AA, Pannu NS, Steiner RA, Nicholls RA, Winn MD, Long F, Vagin AA. 2011. REFMAC5 for the refinement of macromolecular crystal structures. Acta Crystallogr D Biol Crystallogr 67: 355-367.

Nikopoulos K, Venselaar H, Collin RW, Riveiro-Alvarez R, Boonstra FN, Hooymans JM, Mukhopadhyay A, Shears D, van Bers M, de Wijs IJ, et al. 2010. Overview of the mutation spectrum in familial exudative vitreoretinopathy and Norrie disease with identification of 21 novel variants in FZD4, LRP5, and NDP. Hum Mutat 31: 656-666.

Nile AH, Mukund S, Stanger K, Wang W, Hannoush RN. 2017. Unsaturated fatty acyl recognition by Frizzled receptors mediates dimerization upon Wnt ligand binding. Proc Natl Acad Sci 114: 4147-4152.

Pfleger KD, Eidne KA. 2005. Monitoring the formation of dynamic G-protein-coupled receptor-protein complexes in living cells. Biochem J 385: 625-637.

Povelones M, Nusse R. 2005. The role of the cysteine-rich domain of Frizzled in Wingless-Armadillo signaling. EMBO I 24: 3493-3503.

Rios-Esteves J, Resh MD. 2013. Stearoyl CoA desaturase is required to produce active, lipid-modified Wnt proteins. Cell Rep 4: 1072-1081.

Schwarz-Romond T, Fiedler M, Shibata N, Butler PJ, Kikuchi A, Higuchi Y, Bienz M. 2007. The DIX domain of Dishevelled confers Wnt signaling by dynamic polymerization. Nat Struct Mol Biol 14: 484-492.

Shahi P, Park D, Pond AC, Seethammagari M, Chiou SH, Cho K, Carstens JL, Decker WK, McCrea PD, Ittmann MM, et al. 2012. Activation of Wnt signaling by chemically induced dimerization of LRP5 disrupts cellular homeostasis. PLOS One 7: e30814.

Shen G, Ke J, Wang Z, Cheng Z, Gu X, Wei Y, Melcher K, Xu HE, $\mathrm{Xu}$ W. 2015. Structural basis of the Norrin-Frizzled 4 interaction. Cell Res 25: 1078-1081.

Simons M, Gault WJ, Gotthardt D, Rohatgi R, Klein TJ, Shao Y, Lee HJ, Wu AL, Fang Y, Satlin LM, et al. 2009. Electrochemical cues regulate assembly of the Frizzled/Dishevelled complex at the plasma membrane during planar epithelial polarization. Nat Cell Biol 11: 286-294.

Takada R, Satomi Y, Kurata T, Ueno N, Norioka S, Kondoh H, Takao T, Takada S. 2006. Monounsaturated fatty acid modification of Wnt protein: its role in Wnt secretion. Dev Cell 11: 791-801.

Toomes C, Bottomley HM, Scott S, Mackey DA, Craig JE, Appukuttan B, Stout JT, Flaxel CJ, Zhang K, Black GC, et al. 2004. Spectrum and frequency of FZD4 mutations in familial exudative vitreoretinopathy. Invest Ophthalmol Vis Sci 45: 2083-2090.

Uren A, Reichsman F, Anest V, Taylor WG, Muraiso K, Bottaro DP, Cumberledge S, Rubin JS. 2000. Secreted frizzled-related protein-1 binds directly to Wingless and is a biphasic modulator of Wnt signaling. J Biol Chem 275: 4374-4382.

Vermeulen L, De Sousa EMF, van der Heijden M, Cameron K, de Jong JH, Borovski T, Tuynman JB, Todaro M, Merz C, Rodermond $\mathrm{H}$, et al. 2010. Wnt activity defines colon cancer stem cells and is regulated by the microenvironment. Nat Cell Biol 12: 468-476.

Willert K, Brown JD, Danenberg E, Duncan AW, Weissman IL, Reya T, Yates JR III, Nusse R. 2003. Wnt proteins are lipidmodified and can act as stem cell growth factors. Nature 423: 448-452.

Winn MD, Ballard CC, Cowtan KD, Dodson EJ, Emsley P, Evans PR, Keegan RM, Krissinel EB, Leslie AG, McCoy A, et al. 2011. Overview of the CCP4 suite and current developments. Acta Crystallogr D Biol Crystallogr 67: 235-242.

Xu Q, Wang Y, Dabdoub A, Smallwood PM, Williams J, Woods C, Kelley MW, Jiang L, Tasman W, Zhang K, et al. 2004. Vascular development in the retina and inner ear: control by Norrin and Frizzled-4, a high-affinity ligand-receptor pair. Cell 116: $883-895$.

Yang E, Tacchelly-Benites O, Wang Z, Randall MP, Tian A, Benchabane H, Freemantle S, Pikielny C, Tolwinski NS, Lee E, et al. 2016. Wnt pathway activation by ADP-ribosylation. Nat Commun 7: 11430.

Zhang Y, Appleton BA, Wiesmann C, Lau T, Costa M, Hannoush RN, Sidhu SS. 2009. Inhibition of Wnt signaling by Dishevelled PDZ peptides. Nat Chem Biol 5: 217-219. 


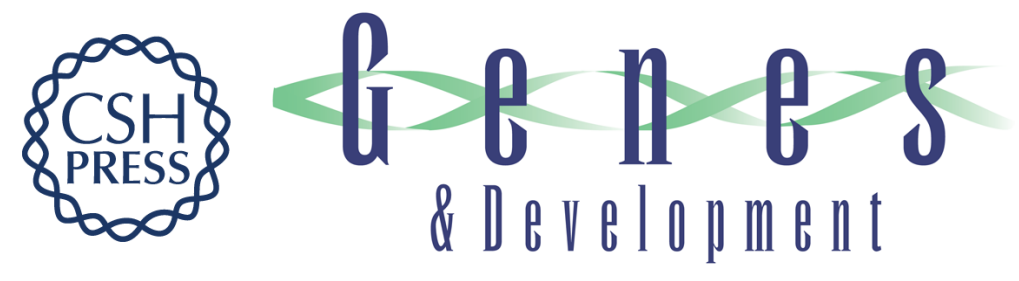

\section{Wnt5a promotes Frizzled-4 signalosome assembly by stabilizing cysteine-rich domain dimerization}

Zachary J. DeBruine, Jiyuan Ke, Kaleeckal G. Harikumar, et al.

Genes Dev. 2017, 31: originally published online May 25, 2017

Access the most recent version at doi:10.1101/gad.298331.117

\section{Supplemental http://genesdev.cshlp.org/content/suppl/2017/05/25/gad.298331.117.DC1 \\ Material}

Related Content

The SIAH E3 ubiquitin ligases promote $\mathrm{Wnt} /{ }^{2}$-catenin signaling through mediating Wnt-induced Axin degradation

Lei Ji, Bo Jiang, Xiaomo Jiang, et al.

Genes Dev. May , 2017 31: 904-915

References This article cites 54 articles, 18 of which can be accessed free at: http://genesdev.cshlp.org/content/31/9/916.full.html\#ref-list-1

Articles cited in: http://genesdev.cshlp.org/content/31/9/916.full.htmI\#related-urls

Creative This article is distributed exclusively by Cold Spring Harbor Laboratory Press for the first Commons six months after the full-issue publication date (see

License http://genesdev.cshlp.org/site/misc/terms.xhtml). After six months, it is available under a Creative Commons License (Attribution-NonCommercial 4.0 International), as described at http://creativecommons.org/licenses/by-nc/4.0/.

Email Alerting Receive free email alerts when new articles cite this article - sign up in the box at the top Service right corner of the article or click here.

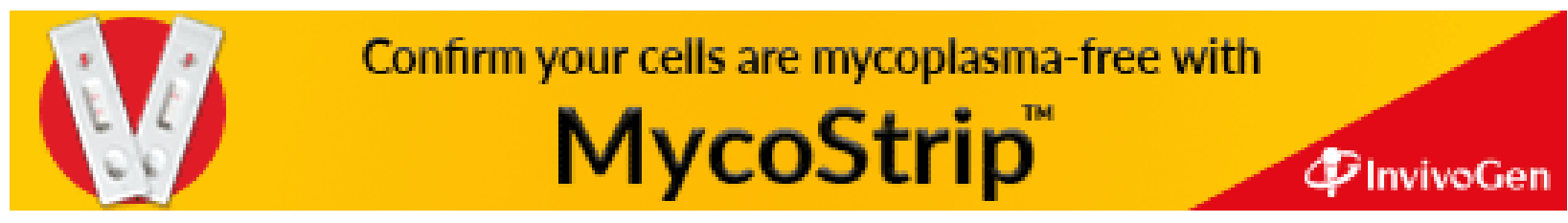

